\title{
Research Paper: Effectiveness of Drama Therapy on Social Skills of Autistic Children
}

\author{
Saeed Rahimi Pordanjani ${ }^{1^{*}}$ (iD)
}

1. Department of Human Sciences, Faculty of Psychology, Shahre Kord Branch, Islamic Azad University, Shahrekord, Iran

\begin{tabular}{|c|c|}
\hline $\begin{array}{l}\text { Use your device to scan } \\
\text { and read the article online }\end{array}$ & \\
\hline 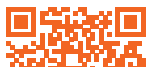 & $\begin{array}{l}\text { Crtation: Rahimi Pordanjani, S. (2021). Effectiveness of Drama Therapy on Social Skills of Autistic Children. Journal of } \\
\text { Practice in Clinical Psychology, 9(1), 9-18. https://doi.org/10.32598/jpcp.9.1.344.1 }\end{array}$ \\
\hline 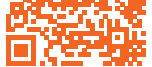 & dol'https://doi.org/10.32598/jpcp.9.1.344.1 \\
\hline
\end{tabular}

\section{(c) (1) (8)}

Article info:

Received: 10 Apr 2020

Accepted: 28 Jul 2020

Available Online: 01 Jan 2021

Keywords:

Drama therapy, Social

skills, Autism, Social action,

Interaction

\section{ABSTRACT}

Objective: Autism spectrum disorder severely damages children's social skills, cognitive functions, and emotional self-regulation. This study aimed to determine the effectiveness of drama therapy on the social skills of children with high-functioning autism.

Methods: The research design was experimental with a pre-test, post-test and a control group. The statistical population included 120 children with high-functioning autism in special education centers in Isfahan City, Iran. For this purpose, 40 children with high-functioning autism disorder were randomly selected by purposive sampling method and using Morgan's table. Then, they were assigned to the experimental and control groups. The experimental group received a drama therapy program, and the control group was placed on a waiting list. The children's instructors completed the Matson social skills questionnaire at pre-test, posttest, and follow-up three months later.

Results: Analysis of the results using repeated measures analysis of variance showed that the drama therapy was effective on the participants' social skills in the experimental group $(\mathrm{P}<0.05)$

Conclusion: Drama therapy will improve their social skills and performance in this field. Therefore, this study's findings might be helpful as practical strategies for practitioners in the field of autism.

\section{"Corresponding Author:}

Saeed Rahimi Pordanjani, PhD.

Address: Department of Human Sciences, Faculty of Psychology, Shahre Kord Branch, Islamic Azad University, Shahrekord, Iran

Tel: +98 (913) 1134903

E-mail: sr.psycho21@gmail.com 


\section{Highlights}

- Drama therapy was effective in enhancing the social skills of children with a high-functioning autism spectrum disorder

- Drama therapy was effective in enhancing self-esteem and peer communication in children with autism spectrum disorder.

- Drama therapy, as a treatment technique for individuals with autism, can decrease their aggression.

\section{Plain Language Summary}

Failure in emotional-social interactions has been identified as a prominent feature of individuals with a high-functioning autism spectrum disorder. It is related to the theory of mind in these individuals. Studies have shown that individuals with autism have significant problems in social participation, initiation of communication, and interaction with others. Drama therapy is among the methods used to treat and reduce the severity of autistic children and adolescents clinical symptoms in recent decades. Drama therapy is empirical and active psychotherapy that includes the drama and theater process. It has been designed to change therapeutic communication and has been actually effective in enhancing social skills and peer communication in children with a high-functioning autism spectrum disorder. In other words, we found that drama therapy can increase social interaction in high-functioning autistic children.

\section{Introduction}

arents' awareness of their child's exceptional and unfavorable circumstances will turn their hopes into despair and create problems (Pisula, 2002). One of these particular circumstances is having a child with autism disorder. Autism disorder refers to a group of neurodevelopmental disorders, including Asperger's, autism, and pervasive developmental disorders, which in the final diagnosis, includes two domains of social interaction damage and behavioral impairment (Sharma, Gonda, \& Tarazi, 2018) that harm the general health (Mikami, Miller, \& Lerner, 2019). Therefore, diagnosis of the problem is essential at an early age, and interventions will be more effective in the case of early diagnosis (Sertcelik, Çağatay, Aközel, \& Gürkan, 2016).

Autism is a life-long disorder and poses significant challenges for individuals, their families, education, and social support organizations (Kempe \& Tissot, 2012; Samson et al., 2014). Failure in emotional-social interactions and serious impairment in social cognition was identified as a prominent feature of individuals with high-functioning autism spectrum disorder (Ip et al., 2018). Cognitive and social failure, including understanding one's moods and emotions, impaired social functioning, and difficulty in initiating communication, building, and developing positive and constructive social relationships with others, are the most critical problems of children with autism (Peterson, Slaughter, Moore, \& Wellman, 2016). Furthermore, persistent failure in the social interactions of autistic individuals leads to impaired visual communication and verbal integration (Karal \& Wolfe, 2018).

Some studies showed that despite the effect of art therapy on improving the social skills of autistic children, the improvement of their social interactions is slow, which is due to their emotional instability (Bharathi, Venugopal, \& Vellingiri, 2019). Furthermore, Carroll (2020) showed that drama therapy had increased the social skills of children with autism. Other studies have shown that group drama therapy is effective in improving social skills and interactions with peers in autistic children but does not create the conditions for active group participation due to lack of social support for them (Wu, Chen, Ma, \& Vomočilová, 2020). Worse than that, conditions such as the outbreak of COVID-19 disease have limited the social communication of individuals, especially children with autism. This condition has been another obstacle to facilitating their social interactions.

These social constraints create substantial issues in the daily lives of autistic children. Therefore, designing and implementing appropriate intervention methods and programs to improve social skills and other psychological components of these individuals are essential (Scattone, 
Tingstrom, \& Wilczynski, 2006). Therefore, methods such as drama therapy were used in recent decades to reduce the severity of clinical symptoms and increase interaction skills and social participation of autistic children and adolescents (Godfrey \& Haythorne, 2013; Maas, 2019).

Drama therapy has its roots in theater techniques and religion (Langley \& Langley, 2018). The theater techniques facilitate personal growth and promote mental health (Godfrey \& Haythorne, 2013; Sajnani, 2017). Conn (2017) found that drama can enhance autistic children's ability to express themselves freely in social interactions and improves their performance in the environment. Other research results showed that drama therapy, as a treatment technique for individuals with autism, could enhance their social skills and facilitate environmental communication (Jonsson et al., 2019; Leather \& Kewley, 2019; Trudel \& Nadig, 2019). As the research in this area is still scanty, there is a need to determine the effectiveness of drama therapy on psychological variables in autistic children.

This study aimed to investigate the effectiveness of drama therapy on social skills of children with highfunctioning autism spectrum disorder and to test the hypothesis of whether drama therapy enhances the social skills dimensions of children with high-functioning autism spectrum disorder such as appropriate social behavior, antisocial behavior, aggression, self-confidence, and communication.

\section{Methods}

The present study is experimental research with Pre-test, Post-test and a control group with a follow-up conducted three months later. The statistical population of this study included 120 children with high-functioning autism spectrum disorder aged 7-12 years who were trained in four public and private special education centers in Isfahan City, Iran. The subjects were assigned to the experimental and control groups using the purposive sampling method. According to the research design and Morgan's table, a sample size of 40 was selected ( 20 in each group). The reason for the selection of 40 subjects was the prediction of attrition. The subjects were divided into the experimental $(n=20)$ and control $(n=20)$ groups according to the inclusion and exclusion criteria after matching.

\section{The inclusion criteria}

The inclusion criteria included having a high-functioning autism spectrum disorder diagnosed by a psychiatrist and Gilliam Autism Rating Scale (GARS), being 7 to 12 years, completing the consent form by parents, and not finding any disorder in the child's medical record such as intellectual developmental disorder.

\section{The exclusion criteria}

The exclusion criteria included missing more than one therapy session, having physical, motor, and sensory (visual-auditory) problems and other behavioral problems based on the child's medical record, expressing uncontrolled aggression of children with an autism spectrum disorder, previous attending in therapy sessions similar to the intervention program used in the present study.

\section{Research tools}

\section{Gilliam Autism Rating Scale (GARS)}

Gilliam Autism Rating Scale (GARS) is a standard instrument based on autism signs and symptoms in the fourth edition of the Mental Disorders Diagnostic Statistical Manual, standardized in 2003 on 1107 samples ( 2 to 22 years old) from 48 US States (Matson, Neal, Worley, Kozlowski, \& Fodstad, 2012; South et al., 2002; Hoffman et al., 2005). It has three subscales that assess communication, social skills, and stereotyped behaviors. Each subscale includes 14 items rated from 0 to 3 by experts, parents, or instructors of these children. The scoring method is that if there is no behavior within 6 hours, the score is 0 ; if it occurs 1 to 2 times in 6 hours, the score is 1 ; if it occurs 3 to 4 times in 6 hours, the score is 2; and if it occurs 5 to 6 times in 6 hours, the score is 3. Studies show a coefficient alpha of 0.90 for repetitive behaviors, 0.89 for communicative skills, 0.93 for social interaction, 0.88 for developmental disorders, and 0.96 for autism semiology. This scale was standardized by experts in Isfahan autism center (Ahmadi, 2011) and the experts approved its face and content validity. GARS questionnaire was used to estimate the construct validity of this scale. The correlation coefficient of these two questionnaires was 0.80 . Its diagnostic validity was determined by comparing subjects to 100 normal children and adolescents through discriminant analysis. The cut-off point was 52, and the sensitivity and specificity of the scale were $99 \%$ and $100 \%$, respectively.

In Iran, the validity of this scale was assessed using the Cronbach alpha coefficient. The Cronbach alpha coefficient for the communication subscale was 0.92 , for the social skills subscale, the coefficient was 0.73 , and for stereotyped behaviors, the coefficient was 0.74. Besides, the total Cronbach alpha was 0.89 (Ahmadi, 2011). 
Matson Social Skills Questionnaire (Messy, 1983)

To assess social skills, we used a 5-question social skills scale (the instructor's form) for 4- to 18-year-old subjects (Matson, Rotatori, \& Helsel, 1983; Matson et al., 2012). The initial form of the scale (Hoffman et al., 2005) had 62 statements checked in the Iranian context by Karami, Gashool, Tayarani Rad, \& Qasemi (2013) and reduced to 56 statements, which described individuals' social skills. Research has shown that the Matson social skills scale has good psychometric properties, high reliability, and acceptable differential validity (Karami et al., 2013).

Matson et al. (1983) used the Cronbach alpha coefficient to assess the reliability of the social skills scale. The Cronbach alpha coefficient and bisection for the whole scale were 0.86 . Regarding the reliability of this test in Iran, the Cronbach alpha coefficient for repetitive behaviors was 0.84 . The scale has 5 subscales, including proper social behavior, non-social behavior, aggression and impulsivity, high self-esteem, and peer communication. In addition to the 5 subscales, a general social skills score was obtained. Scoring is done by a 5-point Likerttype scale ranging from never $=4$ to always $=0$. This test has two forms, parent and instructor, and the instructor form was used in this study.

\section{Study procedure}

After selecting a sample group of autism from autism centers, 40 children with high-functioning autism were selected, according to the inclusion criteria. Since attrition was predictable, all children received a diagnosis letter of autism confirmation from a psychiatrist. After being checked by autism centers, they shared the information regarding high-functioning ratings in assessments that included observation and parent reporting, and the GARS test. After inviting the parents of these children and obtaining their consent, the children were matched according to their age and high-functioning level and randomly divided into the experimental and control groups. Then, their social skills were measured using Matson's social skills test (the instructors' form). After obtaining the parents' agreement, preparing the costume, and furnishing the stage, the best time was chosen for the meeting. Work conditions were the same for all sessions regarding light, temperature, place size, and treatment sessions. Each session was conducted by researchers and three therapeutic assistants, all of whom were trained in the field and were aware of implementing the treatment plan. The control group received no intervention and only received regular training in their programs. The experimental group participated in 12 treatment sessions that lasted two months (90 minutes each session for 12 weeks). These meetings were held once a week. Schedules of sessions were designed based on the children's social skills deficiencies. Finally, after the $12^{\text {th }}$ session, Matson's social skills were re-tested on both experimental and control groups at the Post-test and after three months at the follow-up stage, and the results were collected for statistical analysis. After the drama therapy sessions, another briefing was held with parents, instructors, and children of the control group to familiarize them with the drama therapy method. During the sessions, 10 children left the treatment and were excluded from the final statistical analysis.

\section{Structure of drama therapy sessions}

The training package used in this study was developed from various sources and results of studies on drama therapy (Beadle-Brown et al., 2018; Mpella, Evaggelinou, Koidou, \& Tsigilis, 2019; Trudel \& Nadig, 2019; D'Amico, Lalonde, \& Snow, 2015). Then, it was revised and adjusted. Five faculty members of the Psychology Department checked its content validity. After revising the package based on the faculty members' suggestions, it was sent back to them for final approval. The content validity of the drama therapy was assessed with the kappa coefficient of agreement, and it was found appropriate for children with autism spectrum disorder $(\kappa=0.91)$. The general rules of the sessions included time limits and bans on physical fighting with each other. During the sessions, the researchers attempted to use different approaches of drama therapy for the specific problems of the group the deficiency in social skills.

Twelve sessions were held based on the needs of the subjects, and all sessions were started with a warm-up; this is called the stage of preparation in drama therapy to prepare the subjects for the next stages and included stretching, memory strengthening exercises, group games, and five senses exercises. The second stage is practice and training. At this stage, the subjects are placed in executive and practical training positions. Training is the most critical purpose of this stage, including puppet shows, behavioral training, professional training, participatory training, and animal play. In the third or final stage, the subjects applied the social skills of the previous stages in their social interactions (Table 1).

\section{Results}

Based on Table 2, the Mean \pm SD age in the experimental group was $10.03 \pm 3.14$ years and $10.28 \pm 3.67$ years in the control group. Also, the results showed that in the 
experimental group, the highest rate of parental education was master's, 33\% $(\mathrm{n}=5)$ and bachelor's degree, $33 \%(n=5)$, and the lowest parental education was below diploma, $13 \%(\mathrm{n}=2)$. In the control group, parental education levels of below diploma and diploma were $23 \%$ (in each case, $\mathrm{n}=5$ ), and the rate of parental education with a master's degree was $26 \%(n=2)$.

As can be seen, the mean score of the social skills of the experimental group in the pre-test phase was 9.80, and in the post-test phase, 12.60. The follow-up phase mean was 11.93. The mean of this variable in the control group was 10.13 in the pre-test, 9.87 in the post-test, and 10.07 in the follow-up. Also, the standard deviation of the social skills score of the experimental group was 1.014 in the pre-test phase, 2.26 in the Post-test, and 1.90 in the follow-up phase. The standard deviation of this variable in the control group subjects was 1.407 in the pre-test, 0.91 in the Post-test, and 1.22 in follow-up (Table 2).

According to Table 3, the variances were matched for social skills at the Post-test and follow-up stages $(\mathrm{P}<0.05)$. Table 4 showed that the calculated value of Mauchly's sphericity for social skills is 0.88 ( $\mathrm{P}>0.05)$. Therefore, the equality of the covariance assumption is met. Considering this result and the assumptions, the

Table 1. Summary of drama therapy sessions

\begin{tabular}{|c|c|}
\hline Sessions & Explanations \\
\hline First & $\begin{array}{l}\text { - Introduction: In this session, the researcher introduces himself and the group members to each other. } \\
\text { - Warm-up activities } \\
\text { - The researcher provided a summary of the drama to be performed by the subjects. }\end{array}$ \\
\hline Second & $\begin{array}{l}\text { - The session begins, and the children talk about their events, feelings, and emotions between the two sessions. } \\
\text { - Playwright reading and role analysis: the subjects sit in groups around each other and read the play (when the } \\
\text { fish sinks). } \\
\text { - Discussing feelings and thoughts about the roles. }\end{array}$ \\
\hline Third & $\begin{array}{l}\text {-Warm-up activities } \\
\text { - A masked group of subjects begins to perform the play. }\end{array}$ \\
\hline Fourth & $\begin{array}{l}\text { - The session begins, and the children talk about their events, feelings, and emotions between the two sessions. } \\
\text { - The experimental group continued to perform the play. } \\
\text { - Discussing feelings and thoughts about the roles. }\end{array}$ \\
\hline Fifth & $\begin{array}{l}\text { - The session begins, and the children talk about their events, feelings, and emotions between the two sessions. } \\
\text { - The experimental group continued to perform the play. } \\
\text { - Discussing feelings and thoughts about the roles and getting out of the role. }\end{array}$ \\
\hline Sixth & $\begin{array}{l}\text { - The session begins, and the children talk about their events, feelings, and emotions between the two sessions. } \\
\text { - The final session of the role play and playing the playwright "when the fish sinks", alternating each subject in the } \\
\text { leading role. } \\
\text { - Closure: The subjects are asked to comment on their roles in the play and what they have learned. }\end{array}$ \\
\hline Seventh & $\begin{array}{l}\text { - The session begins, and the children talk about their events, feelings, and emotions between the two sessions. } \\
\text { - The researcher told a summary of the play to be performed by the subjects. }\end{array}$ \\
\hline Eighth & $\begin{array}{l}\text { - The session begins, and the children talk about their events, feelings, and emotions between the two sessions. } \\
\text { - Playwright reading and role analysis: The subjects sit in groups around each other and read the play (Hassani-o- } \\
\text { Dah Barreh). } \\
\text { - The subjects comment on roles. }\end{array}$ \\
\hline Ninth & $\begin{array}{l}\text { - The session begins, and the children talk about their events, feelings, and emotions between the two sessions. } \\
\text { - Discussing feelings and thoughts about the roles and getting out of the role. }\end{array}$ \\
\hline Tent & $\begin{array}{l}\text { - The session begins, and the children talk about their events, feelings, and emotions between the two sessions. } \\
\text { - The continuation of the play is performed by the experimental group. } \\
\text { - Discussing feelings and thoughts about the roles. }\end{array}$ \\
\hline Eleventh & $\begin{array}{l}\text { - The session begins, and the children talk about their events, feelings, and emotions between the two sessions. } \\
\text { - The experimental group completed the play. }\end{array}$ \\
\hline Twelfth & $\begin{array}{l}\text { - The session begins, and the children talk about their events, feelings, and emotions between the two sessions. } \\
\text { - Room arrangement performed in groups and cooperation with the subjects. } \\
\text { - Warm-up activities } \\
\text { - The rhythmic and soft movements are performed with music. } \\
\text { - Hassani-o-Dah Barreh play was performed by the subjects for parents. } \\
\text { - Workflow from the first to the final session is discussed. } \\
\text { - Meeting completion }\end{array}$ \\
\hline
\end{tabular}


Table 2. Mean and standard deviation of social skills in the pre-test, post-test, and follow-up $(n=15)$

\begin{tabular}{ccc}
\hline Stage & Group & Mean \pm SD \\
\hline Pre-test & Control & $10.13 \pm 1.40$ \\
& Experimental & $9.80 \pm 1.01$ \\
Post-test & Control & $9.87 \pm 0.91$ \\
& Experimental & $12.60 \pm 2.26$ \\
Follow-up & Control & $10.07 \pm 1.22$ \\
& Experimental & $11.93 \pm 1.90$ \\
\hline
\end{tabular}

Table 3. The Levene's test for default equality of variances in the pre-test, post-test, and follow-up

\begin{tabular}{cccccc}
\hline Variable & Stage & Levene's test & df1 & df2 & Sig. \\
\hline \multirow{2}{*}{ Social skill } & Post-test & 7.88 & 1 & 28 & 0.009 \\
& Follow-up & 2.90 & 1 & 28 & 0.100 \\
\hline & & & & PLANICAL In PSYCH LOCYY
\end{tabular}

repeated measures Analysis of Variance (ANOVA) was used. Table 5 showed that the drama therapy program significantly affected social skill scores and their dimensions in the Post-test and follow-up stages. Therefore, the research hypotheses are supported, and the therapy increased the social skill scores at post-test and followup stages. To put it differently, drama therapy made a significant difference in the subscales of appropriate social behavior, non-social behavior, aggression, self-esteem, peer communication, and total score.

The means were compared to find out at what level these differences had the most influences. The result showed that in the subscales of proper social behavior, non-social behavior, aggression, self-esteem, and peer communication, the time and interaction of the group were significant in the post-test and follow-up stages. The difference in time level was greater for proper social behavior and communication variables; that is, the symptom of appropriate social behavior and communication was significantly higher than the aggression variable in the Post-test and follow-up stages (group, $\mathrm{P}<0.05$; time $<0.01$; time and group interaction, $\mathrm{P}<0.01, \mathrm{P}<0.05)$. However, there was no significant difference between the post-test and follow-up. The results showed that drama therapy significantly changed the social skill sub-scales in the post-test and follow-up stages in the experimental group, while this increase was not found in the control group.

The results of the Bonferroni test (Table 6) showed that the mean differences of proper social behavior, nonsocial behavior, aggression, self-esteem, and communication are significant comparing pre-test, Post-test, and follow-up. Also, the mean difference at the follow-up stage was significant, indicating that the stability of the treatment outcomes.

\section{Discussion}

Drama therapy effectively enhanced social skills and their components (proper social behavior, non-social behavior, aggression and impulsivity, high self-esteem, and peer communication) in children with a high-functioning autism spectrum disorder. The results of the present study are consistent with the results of Moghaddam, Ravarian, Ershadi, \& Gorji (2019); Miranda, Berenguer,

Table 4. Mauchly's test of sphericity

\begin{tabular}{|c|c|c|c|}
\hline Variable & Mauchly's Test of Sphericity & df & Sig. \\
\hline Social skill & 0.88 & 2 & 0.19 \\
\hline
\end{tabular}


Table 5. Results of repeated measures analysis of variance of social skills dimensions of subjects

\begin{tabular}{|c|c|c|c|c|c|c|c|}
\hline $\begin{array}{l}\text { Sources of } \\
\text { Impact }\end{array}$ & Sources of Change & Sum of Squares & df & Mean Squares & $\mathbf{F}$ & Effect Size & Test Power \\
\hline \multirow{6}{*}{ Group } & Proper social behavior & 134.03 & 2 & 151.72 & $66.16^{*}$ & 0.56 & 1 \\
\hline & Non-social behavior & 423.43 & 2 & 251.21 & $63.46^{*}$ & 0.56 & 1 \\
\hline & Aggression & 387.43 & 2 & 241.12 & $31.89^{*}$ & 0.54 & 1 \\
\hline & High self-esteem & 347.42 & 2 & 231.23 & $41.39^{*}$ & 0.56 & 1 \\
\hline & Communication & 247.42 & 2 & 167.56 & $51.09^{*}$ & 0.56 & 1 \\
\hline & Total score & 356.33 & 2 & 436.62 & $64.36^{*}$ & 0.56 & 1 \\
\hline \multirow{6}{*}{ Time } & Proper social behavior & 226.23 & 2 & 183.71 & $56.06^{* *}$ & 0.59 & 1 \\
\hline & Non-social behavior & 323.43 & 2 & 174.73 & $48.46^{* *}$ & 0.59 & 1 \\
\hline & Aggression & 289.73 & 2 & 166.05 & $29.78^{* *}$ & 0.59 & 1 \\
\hline & High self-esteem & 378.09 & 2 & 167.12 & $41.39^{*}$ & 0.59 & 1 \\
\hline & Communication & 232.01 & 2 & 121.28 & $32.26^{*}$ & 0.56 & 1 \\
\hline & Total score & 378.03 & 2 & 302.25 & $46.33^{*}$ & 0.56 & 1 \\
\hline \multirow{6}{*}{ Group×Time } & Proper social behavior & 118.43 & 2 & 63.71 & $8.31^{*}$ & 0.36 & 0.96 \\
\hline & Non-social Behavior & 212.43 & 2 & 151.71 & $7.46^{*}$ & 0.24 & 1 \\
\hline & Aggression & 223.24 & 2 & 152.78 & $29.78^{*}$ & 0.24 & 1 \\
\hline & High Self-Esteem & 134.10 & 2 & 146.56 & $3.41^{*}$ & 0.34 & 1 \\
\hline & Communication & 231.12 & 2 & 146.56 & $6.61^{*}$ & 0.34 & 1 \\
\hline & Total score & 254.10 & 2 & 146.56 & $7.81 *$ & 0.36 & 1 \\
\hline
\end{tabular}

${ }^{*} \mathrm{P}<0.05,{ }^{* *} \mathrm{P}<0.01$

CLINICAL PSYCH $\cong$ LOGY

Roselló, \& Baixauli (2018), Beadle-Brown et al. (2018), Li, Wang, Guo, \& Li (2015), and D'Amico et al. (2015).

In explaining these findings, it can be stated that socialization is one of the challenges of children with autism (Kempe \& Tissot, 2012). Thus, interacting with others in a meaningful and productive way is essential in life (Cerbo \& Rabi, 2019). The use of creative play enhanced the social interaction and socialization of autism learners. They defined social skills as acquired communityfriendly behaviors that enable the individual to interact with others in a way that evokes positive reactions

Table 6. Bonferroni follow-up test results for the effect of drama therapy on social skills

\begin{tabular}{cccc}
\hline \multirow{2}{*}{ Statistical Index } & & Mean \pm SD & Post-test, Follow-up \\
\cline { 2 - 4 } & Pre-test, Post-test & Pre-test, Follow-up & $1.2 \pm 0.14$ \\
\hline Proper social behavior & $15.18 \pm 4.21$ & $15.12 \pm 3.12$ & $1.3 \pm 0.15$ \\
Non-social behavior & $14.21 \pm 4.02$ & $14.1 \pm 3.84$ & $0.98 \pm 0.1$ \\
Aggression & $13.81 \pm 3.48$ & $12.28 \pm 3.01$ & $1.21 \pm 0.12$ \\
High self-esteem & $15.92 \pm 3.67$ & $15.78 \pm 4.21$ & $1.01 \pm 0.11$ \\
Communication & $14.23 \pm 4.36$ & $13.65 \pm 3.67$ & $1.5 \pm 0.12$ \\
\hline
\end{tabular}


and avoids adverse reactions. In this regard, the results of Watkins (2018), Nowell, Watson, Boyd, \& Klinger (2019), Will et al. (2018), Fernández-Aguayo and PinoJuste (2018), and Crozier and Tincani (2007) showed that indirect behaviors such as play and drama therapy could improve behavior, motivation, and social skills in children with autism. If education is continual and tailors to children's abilities, the persistence of new behaviors results in self-confidence and reduction of inappropriate behaviors (Karnezi \& Tierney, 2014).

Other findings of the present study are that drama therapy effectively enhanced social skills and subscales of proper social behavior, non-social behavior, aggression and impulsivity, self-esteem, and peer communication. A plausible explanation of this hypothesis is that the issue of socialization and the ability to interact with others appropriately and productively is essential at all stages of life. Based on research results of Dogru (2015), Mpella et al. (2019), Beadle-Brown et al. (2018), Trudel and Nadig (2019), D'Amico et al. (2015), and Conn (2017), play and drama can enhance the social skills and motivation associated with it in children with autism. If they continue, they keep the children interacting together and with the instructors. Furthermore, playing roles in the context of the drama reduces existing vacancies and negative emotional states and increases the level of emotional connection and empathy with others (Malhotra, 2019).

Finally, drama therapy provided a model of social skills and appropriate ways of dealing with situations in autistic children in the experimental group. Based on the observational learning paradigm, these models teach new behaviors to these children and improve and organize the target behaviors that exist in their behavioral compartment. Thus, the intervention program could enhance children's social skills in the experimental group and reduce their disturbing behaviors (Scattone et al., 2006; Hartigan, 2012; Klin et al., 2007).

Considering the study's limitations, the number of sample group psychological problems, the subjects' fatigue, and the insufficient time to hold the drama therapy sessions, one must be cautious in generalizing the results. Overall, it is recommended that this therapy be considered as one of the effective methods along with other therapies in autism education and rehabilitation centers.

\section{Conclusion}

Drama therapy will improve children's social skills and performance with an autism spectrum disorder. Therefore, this study's findings might be helpful as practical strategies for the practitioners in this field. Otherwise, play and drama can enhance the social skills and motivation associated with autistic children. These results signify that additional study of drama therapy treatment is needed to make the evidence base for such interventions in this client group.

\section{Ethical Considerations}

\section{Compliance with ethical guidelines}

All ethical principles are considered in this article. The participants were informed of the purpose of the research and its implementation stages. They were also assured about the confidentiality of their information and were free to leave the study whenever they wished, and if desired, the research results would be available to them.

\section{Funding}

This research did not receive any grant from funding agencies in the public, commercial, or non-profit sectors.

\section{Authors' contributions}

All authors equally contributed to preparing this article.

\section{Conflict of interest}

The authors declared no conflict of interest.

\section{References}

Ahmadi, S. J. (2011). Study psychometric indices of Autism Diagnostic Test GARS. Research in Cognitive and Behavioral Sciences, 1(1), 87-104. https://www.sid.ir/en/Journal/ViewPaper. aspx?ID $=559325$

Beadle-Brown, J., Wilkinson, D., Richardson, L., Shaughnessy, N., Trimingham, M., \& Leigh, J., et al. (2018). Imagining Autism: Feasibility of a drama-based intervention on the social, communicative and imaginative behaviour of children with $\mathrm{Au}$ tism. Autism, 22(8), 915-27. [DOI:10.1177/1362361317710797] [PMID]

Bharathi, G., Venugopal, A., \& Vellingiri, B. (2019). Music therapy as a therapeutic tool in improving the social skills of autistic children. The Egyptian Journal of Neurology, Psychiatry and Neurosurgery, 55(1), 44. https://link.springer.com/article/10.1186/s41983-019-0091-x

Carroll, R. (2020). An exploration into the success and improvement of drama-play programs for individuals with Autism Spectrum Disorder. No Data. https://repository.tcu.edu/ handle/116099117/40258 
Cerbo, S. N., \& Rabi, N. M. (2019). Drama activities as tool for socialization of learners with Autism. International Journal of Academic Research in Business And Social Sciences, 9(6), 1250-61. [DOI:10.6007/IJARBSS/v9-i6/6102]

Conn, C. (2017). Using drama with children on the Autism spectrum. London: Speechmark. [DOI:10.4324/9781315149035]

Crozier, S., \& Tincani, M. (2007). Effects of social stories on prosocial behavior of preschool children with Autism spectrum disorders. Journal of Autism and Developmental Disorders, 37(9), 1803-14. [DOI:10.1007/s10803-006-0315-7] [PMID]

D'Amico, M., Lalonde, C., \& Snow, S. (2015). Evaluating the efficacy of drama therapy in teaching social skills to children with Autism Spectrum Disorders. Drama Therapy Review, 1(1), 21-39. [DOI:10.1386/dtr.1.1.21_1]

Dogru, S. S. Y. (2015). The Effect of creative drama on pre-teaching skills and social communication behaviors of children with Autism. Studies on Ethno-Medicine, 9(2), 181-9. [DOI:10.10 80/09735070.2015.11905433]

Fernández-Aguayo, S., \& Pino-Juste, M. (2018). Drama therapy and theater as an intervention tool: Bibliometric analysis of programs based on drama therapy and theater. The Arts in Psychotherapy, 59, 83-93. [DOI:10.1016/j.aip.2018.04.001]

Godfrey, E., \& Haythorne, D. (2013). Benefits of dramatherapy for Autism Spectrum Disorder: a qualitative analysis of feedback from parents and teachers of clients attending Roundabout dramatherapy sessions in schools. Dramatherapy, 35(1), 20-8. [DOI:10.1080/02630672.2013.773131]

Hartigan, P. (2012). Using theater to teach social skills: Researchers document improvements for children with Autism. Education Digest: Essential Readings Condensed for Quick Review, 77(9), 30-4. https:/ / eric.ed.gov/?id=EJ999421

Hoffman, C. D., Sweeney, D. P., Gilliam, J. E., Apodaca, D. D. Lopez-Wagner, M. C., \& Castillo, M. M. (2005). Sleep problems and symptomology in children with Autism. Focus on Autism and Other Developmental Disabilities, 20(4), 194-200. [D OI:10.1177/10883576050200040101]

Ip, H. H. S., Wong, S. W. L., Chan, D. F. Y., Byrne, J., Li, C., \& Yuan, V. S. Y., et al. (2018). Enhance emotional and social adaptation skills for children with Autism spectrum disorder: A virtual reality enabled approach. Computers E Education, 117, 1-15. [DOI:10.1016/j.compedu.2017.09.010]

Jonsson, U., Olsson, N. C., Coco, C., Görling, A., Flygare, O., Råde, A., et al. (2019). Long-term social skills group training for children and adolescents with Autism spectrum disorder: A randomized controlled trial. European Child $\mathcal{E}$ Adolescent Psychiatry, 28(2), 189-201. [DOI:10.1007/s00787-018-1161-9] [PMID] [PMCID]

Karal, M. A., \& Wolfe, P. S. (2018). Social story effectiveness on social interaction for students with Autism: A review of the literature. Education and Training in Autism and Developmental Disabilities, 53(1), 44-58. https:/ / eric.ed.gov/?id=EJ1179142

Karami, B., Gashool, M., Tayarani Rad, A., \& Qasemi, S. (2013). The matson evaluation of social skills with youngsters-II (MESSY-II) and Its adaptation for Iranian children and adolescents with intellectual disability. Practice in Clinical Psychology, 1(4), 239-45. http:/ /jpcp.uswr.ac.ir/article-1-128-en.html

Karnezi, H., \& Tierney, K. (2014). Cognitive behavior drama: an innovative intervention model that combines established psychological methods with the art form of drama to provide young children on the Autism spectrum with the motivation and confidence to overcome their fears. Advances in Research 2(7), 393-408. [DOI:10.9734/AIR/2014/8643]

Kempe, A., \& Tissot, C. (2012). The use of drama to teach social skills in a special school setting for students with autism. Support for Learning, 27(3), 97-102. [DOI:10.1111/j.14679604.2012.01526.x]

Klin, A., Saulnier, C. A., Sparrow, S. S., Cicchetti, D. V., Volkmar, F. R., \& Lord, C. (2007). Social and communication abilities and disabilities in higher functioning individuals with Autism spectrum disorders: The Vineland and the ADOS Journal of Autism and developmental Disorders, 37(4), 748-759. [DOI:10.1007/s10803-006-0229-4] [PMID]

Langley, D. M., \& Langley, G. E. (2018). Dramatherapy and psychiatry. London: Routledge. [DOI:10.4324/9780429460371]

Leather, J., \& Kewley, S. (2019). Assessing drama therapy as an intervention for recovering substance users: A systematic review. Journal of Drug Issues, 49(3), 545-58. [DOI:10.1177/0022042619845845]

Li, J., Wang, D., Guo, Z., \& Li, K. (2015). Using psychodrama to relieve social barriers in an autistic child: A case study and literature review. International Journal of Nursing Sciences, 2(4), 402-7. [DOI:10.1016/j.ijnss.2015.08.008]

Maas, C. (2019). Improvisational theatre and occupational therapy for children with Autism spectrum disorder. International Journal of Disability, Development and Education, 68(1), 1-16. [DOI:10.1080/1034912X.2019.1634793

Malhotra, B. (2019). Art therapy with puppet making to promote emotional empathy for an adolescent with Autism. Art Therapy, 36(4), 1-9. [DOI:10.1080/07421656.2019.1645500]

Matson, J. L., Neal, D., Worley, J. A., Kozlowski, A. M., \& Fodstad, J. C. (2012). Factor structure of the Matson evaluation of social skills with youngsters-II (MESSY-II). Research in Developmental Disabilities, 33(6), 2067-71. [DOI:10.1016/j. ridd.2010.09.026] [PMID]

Matson, J. L., Rotatori, A. F., \& Helsel, W. J. (1983). Development of a rating scale to measure social skills in children: The matson evaluation of social skills with youngsters (MESSY). Behaviour Research and Therapy, 21(4), 335-40. [DOI:10.1016/00057967(83)90001-3]

Mikami, A. Y., Miller, M., \& Lerner, M. D. (2019). Social functioning in youth with attention-deficit/hyperactivity disorder and Autism spectrum disorder: Transdiagnostic commonalities and differences. Clinical Psychology Review, 68, 54-70 [DOI:10.1016/j.cpr.2018.12.005] [PMID]

Miranda, A., Berenguer, C., Roselló, B., \& Baixauli, I. (2018). Relationships between the social communication questionnaire and pragmatic language, socialization skills, and behavioral problems in children with Autism spectrum disorders. Applied neuropsychology Child, 9(2), 141-52. [DOI:10.1080/21622965.201 8.1550403] [PMID]

Moghaddam, K., Ravarian, A., Ershadi, F. S., \& Gorji, A. (2019) [The importance of theatre therapy (psychodrama) in the treatment of children and adolescents with Autism spectrum disorder (Persian)]. The Neuroscience Journal of Shefaye Khatam, 7(2) 107-15. [DOI:10.29252/shefa.7.2.107] 
Mpella, M., Evaggelinou, C., Koidou, E., \& Tsigilis, N. (2019). The effects of a theatrical play programme on social skills development for young children with Autism Spectrum Disorders. International Journal of Special Education, 33(4), 828-45. https:// eric.ed.gov/?id=EJ1219307

Nowell, S. W., Watson, L. R., Boyd, B., \& Klinger, L. G. (2019). Efficacy study of a social communication and self-regulation intervention for school-age children with Autism spectrum disorder: A randomized controlled trial. Language, Speech, and Hearing Services in Schools, 50(3), 416-33. [DOI:10.1044/2019_ LSHSS-18-0093] [PMID] [PMCID]

Peterson, C., Slaughter, V., Moore, C., \& Wellman, H. M. (2016). Peer social skills and theory of mind in children with Autism, deafness, or typical development. Developmental psychology, 52(1), 46. [DOI:10.1037/a0039833] [PMID]

Pisula, E. (2002). [Parents of children with Autism: Recent research findings (Polish)]. Psychiatria Polska, 36(1), 95-108. [PMID]

Sajnani, N. (2017). Advancing theory and technique in drama therapy. Drama Therapy Review, 3(2), 161-4. [DOI:10.1386/ dtr.3.2.161_2]

Samson, A. C., Phillips, J. M., Parker, K. J., Shah, S., Gross, J. J., \& Hardan, A. Y. (2014). Emotion dysregulation and the core features of autism spectrum disorder. Journal of Autism and developmental Disorders, 44(7), 1766-72. [DOI:10.1007/s10803-0132022-5] [PMID]

Scattone, D., Tingstrom, D. H., \& Wilczynski, S. M. (2006). Increasing appropriate social interactions of children with autism spectrum disorders using Social Stories ${ }^{\mathrm{TM}}$. Focus on Autism and Other Developmental Disabilities, 21(4), 211-22. [DOI:10.1177/10 883576060210040201]

Sertcelik, M., Çağatay, U., Aközel, A. Ş., \& Gürkan, C. K. (2016) A child with Kabuki Syndrome and Autism Spectrum disorder. Archives of Neuropsychiatry, 53(3), 280. [DOI:10.5152/ npa.2015.10099] [PMID] [PMCID]

Sharma, S. R., Gonda, X., \& Tarazi, F. I. (2018). Autism spectrum disorder: Classification, diagnosis and therapy. Pharmacology \& Therapeutics, 190, 91-104. [DOI:10.1016/j. pharmthera.2018.05.007] [PMID]

Shaughnessy, N., \& Barnard, P. (2019). Performing psychologies: imagination, creativity and dramas of the mind. London: Bloomsbury Publishing. [DOI:10.1353/tj.2019.0120]

South, M., Williams, B. J., McMahon, W. M., Owley, T., Filipek, P. A., \& Shernoff, E., et al. (2002). Utility of the Gilliam Autism Rating Scale in research and clinical populations. Journal of Autism and developmental Disorders, 32(6), 593-9. [DOI:10.1023/A:1021211232023] [PMID]

Trudel, C., \& Nadig, A. (2019). A role-play assessment tool and drama-based social skills intervention for adults with autism or related social communication difficulties. Dramatherapy, 40(1), 41-60. [DOI:10.1177/0263067219834712]

Watkins, L. B. (2018). Improving social interaction between students with Autism spectrum disorder and their peers in inclusive settings. Austin: The University of Texas. http://hdl. handle.net/2152/63377

Will, M. N., Currans, K., Smith, J., Weber, S., Duncan, A., \& Burton, J., et al. (2018). Evidenced-based interventions for children with Autism Spectrum Disorder. Current Problems in Pediatric and Adolescent Health Care, 48(10), 234-49. [DOI:10.1016/j.cppeds.2018.08.014] [PMID]

Wu, J., Chen, K., Ma, Y., \& Vomočilová, J. (2020). Early intervention for children with intellectual and developmental disability using drama therapy techniques. Children and Youth Services Review, 109, 104689. https://www.sciencedirect.com/ science/article/abs/pii/S019074091931254X 